\title{
Vitamin Status among Breastfed Infants in Bhaktapur, Nepal
}

\author{
Manjeswori Ulak ${ }^{1, *}$, Ram K. Chandyo ${ }^{2}$, Andrew L. Thorne-Lyman ${ }^{3,4}$, Sigrun Henjum ${ }^{5}$, \\ Per M. Ueland ${ }^{6}$, Øivind Midttun ${ }^{7}$, Prakash S. Shrestha ${ }^{1}$, Wafaie W. Fawzi ${ }^{3,8}$, Lauren Graybill ${ }^{8}$ \\ and Tor A. Strand ${ }^{2,9}$ \\ 1 Department of Child Health, Institute of Medicine, Tribhuvan University, Maharajgunj, P.O. Box 1524, \\ Kathmandu 44600, Nepal; prakashsunder@hotmail.com \\ 2 Centre for International Health, University of Bergen, P.O. Box 7800, 5020 Bergen, Norway; \\ ram.chandyo@uib.no (R.K.C.); tor.strand@uib.no (T.A.S.) \\ 3 Department of Nutrition, Harvard T.H. Chan School of Public Health, 665 Huntington Avenue, Boston, \\ MA 02115, USA; a.thorne-lyman@cgiar.org (A.L.T.-L.); mina@hsph.harvard.edu (W.W.F.) \\ 4 World Fish, Malaysia, GPO 10670, Bayan Lepas, Penang 11960, Malaysia \\ 5 Oslo and Akershus University College of Applied Sciences, P.O. Box 4, St. Olavs plass, 0130 Oslo, Norway; \\ sigrun.henjum@hioa.no \\ 6 Section for Pharmacology, Department of Clinical Science, University of Bergen, 5020 Bergen, Norway; \\ per.ueland@ikb.uib.no \\ 7 Bevital AS, c/o Helse Bergen, Jonas Lies veg 87, 5020 Bergen, Norway; bjorn.midttun@uib.no \\ 8 Department of Epidemiology and Global Health and Population, \\ Harvard T.H. Chan School of Public Health, 665 Huntington Avenue, Boston, MA 02115, USA; \\ lag111@mail.harvard.edu \\ 9 Innlandet Hospital Trust, 2629 Lillehammer, Norway \\ * Correspondence: manjeswori@gmail.com; Tel.: +977-01-4412202; Fax: +977-01-4418189
}

Received: 18 November 2015; Accepted: 3 March 2016; Published: 8 March 2016

\begin{abstract}
Vitamin deficiencies are known to be common among infants residing in low- and middle-income countries but relatively few studies have assessed several biochemical parameters simultaneously. The objective of the study was to describe the status of vitamins $\left(\mathrm{A}, \mathrm{D}, \mathrm{E}, \mathrm{B}_{6}\right.$, $\mathrm{B}_{12}$ and folate) in breastfed infants. We measured the plasma concentrations of trans retinol, 25 hydroxy vitamin $\mathrm{D}, \alpha$-tocopherol, pyridoxal $5^{\prime}$-phosphate, cobalamin, folate, methylmalonic acid, homocysteine, hemoglobin and C-reactive protein from 467 randomly selected infants. One in five $(22 \%)$ was deficient in at least one vitamin. Mean (SD) plasma folate concentration was 73 (35) $\mathrm{nmol} / \mathrm{L}$, and no infant in the sample was folate deficient. Vitamin $\mathrm{B}_{6}$ deficiency and vitamin $\mathrm{B}_{12}$ deficiency was found in $22 \%$ and $17 \%$ of the infants, respectively. Elevated plasma methylmalonic acid or total homocysteine concentration was found in $82 \%$ and $62 \%$ of infants, respectively. Fifteen percent of infants were vitamin A deficient and $65 \%$ were marginally deficient in vitamin A. Fewer than $5 \%$ of infants had low plasma vitamin D concentration or vitamin E concentration ( $\alpha$-tocopherol $<9.3 \mu \mathrm{mol} / \mathrm{L}$ ). Our results illustrate the importance of continued supplementation campaigns and support the expansion of food fortification and dietary diversification programs that target children and women in Nepal.
\end{abstract}

Keywords: vitamins; infant; Nepal; methylmalonic acid; homocysteine

\section{Introduction}

Vitamins and minerals are essential for children's physical health, growth and cognitive development [1,2]. Worldwide more than two billion people, mostly residing in low-income countries, are deficient in key vitamins and minerals [3]. The estimated prevalence of vitamin deficiencies 
among Nepalese children has ranged from $6 \%$ to $59 \%$ [4]. Avoiding vitamin deficiencies is particularly important in infants as this period represents an extremely important time for growth and development and complementary foods often lack the required nutrient content and quality [5].

Vitamin A deficiency, even in subclinical form, increases the risk of childhood morbidity and mortality [6,7]. In Nepal, a recent national survey reported that only $47 \%$ of children aged 6 to 23 months consumed foods rich in vitamin A on the day prior to the interview [8]. Vitamin D is important for calcium metabolism, bone health, and immunity $[9,10]$, and may also be important in cognitive development [11] and for preventing infections, including pneumonia [12]. Vitamin D deficiency is more common among infants who have poor sunlight exposure or whose mothers are deficient [13]. Vitamin $\mathrm{E}$ is required for modulating oxidative stress [14]. Folate, vitamin $\mathrm{B}_{12}$, and vitamin $B_{6}$ are crucial for the methylation cycle. Deficiencies of these vitamins may affect growth and cognitive performance in children [15-17]. Most of these vitamins are also essential for antibody production and for the integrity of the gastrointestinal and respiratory epithelium [18]. Prevention of common micronutrient deficiencies in the first two years of age is an important priority for low income countries [19]. However, little data exists on the prevalence of various micronutrient deficiencies and how the plasma concentration of their biomarkers varies throughout infancy. The purpose of this study was to describe the status of key vitamins (A, D, E, B,$B_{12}$ and folate, and the biomarkers total homocysteine and methylmalonic acid) in a random sample of breastfed infants, from two months of age, residing in Bhaktapur, Nepal.

\section{Subjects and Methods}

\subsection{Subjects}

The study was conducted in Bhaktapur municipality located $15 \mathrm{~km}$ east from the capital of Nepal (Kathmandu). Bhaktapur is a semi-urban community of approximately 80,000 inhabitants who predominantly belong to the Newar ethnic group. Agriculture is an important component of the majority of livelihoods among residents of the Bhaktapur municipality. Similar to the rest of Nepal, diet in Bhaktapur consists primarily of rice and lentils, with seasonal availability of green leafy vegetables. Meat, fish and dairy products are not regularly consumed even though most of the people are not vegetarians. Most of the pregnant women ( $90 \%)$ attend regular antenatal visits at different health centers in the community and receive iron (elemental iron of $60 \mathrm{mg}$ ) with folic acid $(400 \mu \mathrm{g})$ usually from the first trimester, and also calcium tablets $(500 \mathrm{mg})$ from the second trimester which are continued up to 45 days postpartum [20]. The Government of Nepal distributes iron and folic acid free of cost but most of the pregnant mothers purchase it from the local pharmacy and composition may vary from one brand to another. The Government of Nepal also distributes bi-annual vitamin A supplementation to children from six months to five years.

\subsection{Enrollment Procedure}

Mother-infant pairs were identified thorough a community based surveillance. A cluster sampling procedure was used, in which we randomly selected 66 out of 160 geographic areas (called Toles) in Bhaktapur municipality; from these Toles, we generated a list of all eligible mother-infant pairs and randomly approached 582 pairs whom we invited to participate in this study. They were eligible to participant if the infant was from two to 12 months of age, currently breastfed, and were not diagnosed with an acute infection or a chronic or congenital disease. Details of this process can be found elsewhere [20]. A total of 500 mother-infant pairs were enrolled in the study from January 2008 to February 2009; vitamin status was analysed only in 467 infants as the volumes of the plasma samples were not sufficient from 33 enrolled infants.

Upon selection, mothers were asked to bring their children to Siddhi Memorial Hospital for administration of the household questionnaire, physical examination, anthropometric measurement, and blood collection. All mothers gave informed consent before participating in the study. Ethical 
clearance was approved from the institutional review board at the Institute of Medicine, Kathmandu, Nepal and the Regional Research Ethical Committee in Norway. The length of infants were measured with locally made wooden boards that were periodically calibrated. Infant's weight-for-age, height-for age, and weight-for-height z-scores were calculated based on WHO growth standards [21]. Perinatal characteristics, as well as birth weights, were recorded based on mother's recall or birth records. We defined breastfeeding according to the recent WHO guidelines. Exclusive breastfeeding was defined when the infant had received only breast milk form his/her mother or a wet nurse, or expressed breast milk and no other liquids or solid with the exception of drops of syrup consisting of vitamins, mineral supplements or medicines [22]. All forms were manually checked for inconsistencies and data was double entered.

\subsection{Sample Size Calculations}

Four hundred and fifty individuals were required to detect a $25 \%$ prevalence of vitamin deficiency with an absolute precision of 5\%. Assuming a 10\% loss-to-follow-up, we therefore enrolled 500 children.

\subsection{Blood Sampling and Biochemical Analysis}

Approximately $3 \mathrm{~mL}$ of whole blood was taken from the cubital vein using polypropylene tubes with lithium heparin (Sarstedt, Germany). We measured hemoglobin $(\mathrm{Hb})$ on HemoCue (HemoCue, Vedbæk, Denmark) immediately after blood collection. The HemoCue was calibrated on a regular basis. The samples were then centrifuged $(760 \times \mathrm{g}$, for $10 \mathrm{~min}$, room temperature) and plasma was allocated into polypropylene vials (Eppendorf, Hinz, Germany). Samples were stored at $-20{ }^{\circ} \mathrm{C}$ at the field site laboratory until they were transported with an ice pack to the central laboratory in Kathmandu at the end of each day. There, samples were stored at $-80{ }^{\circ} \mathrm{C}$ until transport on dry ice to Norway. Blood samples were analysed at the Bevital laboratory, Bergen, Norway. Plasma vitamin $B_{12}$ and folate levels were determined by microbiological assay based on growth support of Lactobacillus leichmannii and Lactobacillus casei, [23,24] respectively. These assays were adapted to a microtiter plate format and carried out by a robotic workstation; the within day coefficients of variation were 5\% [25]. Plasma methylmalonic acid (MMA) and total homocysteine (tHcy) were analyzed using a gas chromatography mass spectrometry based on methylchloroformate derivatization [26]. Plasma vitamin $\mathrm{B}_{6}$, in the form pyridoxal 5'-phosphate (PLP), and fat soluble vitamins $A, D$, and $E$, in the form of trans retinol, 25 hydroxyvitamin D 25(OH)D and alpha-tocopherol, respectively, were measured by liquid chromatography-tandem mass spectrometry $[27,28]$. Throughout the paper, we use $25(\mathrm{OH}) \mathrm{D}$ to describe the sum of $25(\mathrm{OH}) \mathrm{D}_{2}$ and $25(\mathrm{OH}) \mathrm{D}_{3}$, and plasma vitamin A for all-trans retinol values. Plasma C-reactive protein (CRP) was analysed by turbidimetric immunoassay (Tina-Quant, Roche, Germany) on Hitachi 917 (Tokyo) at the laboratory of clinical biochemistry, Haukeland University hospital in Bergen, Norway. Definitions and cut-off points for vitamin deficiencies, MMA, tHcy in plasma, and anemia are shown in Table 1.

Table 1. Definition and cut-off values of anemia and plasma concentration of vitamin and metabolites among 467 infants in Bhaktapur, Nepal.

\begin{tabular}{ccc}
\hline Definition & Indicators & Cut off \\
\hline Anemia [29] & Hemoglobin $(\mathrm{Hb})$ & $<110 \mathrm{~g} / \mathrm{L}$ \\
Altitude adjusted anemia [30] & $\mathrm{Hb}$ & $<113 \mathrm{~g} / \mathrm{L}$ \\
Vitamin B12 deficiency [31] & Cobalamin & $<150 \mathrm{pmol} / \mathrm{L}$ \\
Marginal vitamin B12 deficiency & Cobalamin & $<200 \mathrm{pmol} / \mathrm{L}$ \\
Folate deficiency [31] & plasma folate & $<10 \mathrm{nmol} / \mathrm{L}$ \\
Vitamin B6 deficiency [32,33] & pyridoxal 5'-phosphate & $<20 \mathrm{nmol} / \mathrm{L}$ \\
Vitamin A deficiency [33,34] & trans retinol & $<0.70 \mu \mathrm{mol} / \mathrm{L}$ \\
Marginal vitamin A deficiency [34] & trans retinol & $<1.05 \mu \mathrm{mol} / \mathrm{L}$ \\
\hline
\end{tabular}


Table 1. Cont.

\begin{tabular}{ccc}
\hline Definition & Indicators & Cut off \\
\hline Vitamin D deficiency [35] & 25 hydroxyvitamin D (25(OH)D) & $<50 \mathrm{nmol} / \mathrm{L}$ \\
Marginal Vitamin D deficiency & $25(\mathrm{OH}) \mathrm{D}$ & $<75 \mathrm{nmol} / \mathrm{L}$ \\
Vitamin E deficiency [36] & $\alpha$-tocopherol & $<9.3 \mu \mathrm{mol} / \mathrm{L}$ \\
Marginal vitamin E deficiency & $\alpha$-tocopherol & $<18.9 \mu \mathrm{mol} / \mathrm{L}$ \\
Hyperhomocysteinemia [17] & Total homocysteine (tHcy) & $>10 \mu \mathrm{mol} / \mathrm{L}$ \\
Hypermethylmalonic acidemia & Methylmalonic acid (MMA) & $>0.28 \mu \mathrm{mol} / \mathrm{L}$ \\
\hline
\end{tabular}

\subsection{Data Analysis}

The statistical analyses were performed using Stata, version 13 (Stata Corp. 2013. Stata Statistical Software: College Station, TX: Stata Corp LP) adjusted for clustering sample design using the SVY commands. We present mean, median, and interquartile range (IQR) of vitamins $A, B_{6}, B_{12}$, folate, $D$, $\mathrm{E}$, and metabolites tHcy and MMA. The prevalence of vitamin deficiencies was presented with $95 \%$ confidence intervals. We evaluated differences in the levels of vitamin deficiencies across ages; a $p$ value of $<0.05$ was considered to reflect a statistically significant difference. Spearman correlation analysis was undertaken to investigate the association with different vitamins and age. As the concentrations of vitamin biomarkers might be influenced based on presence of clinical or subclinical infection, we also present association of CRP with the plasma vitamin concentrations [37].

\section{Results}

\subsection{Baseline}

Socio-demographic and anthropometric parameters of enrolled infants are shown in Table 2. The study achieved almost equal enrolment of male and female infants. The mean age (SD) of infants was 6.8 (2.9) months; $45 \%$ children were six months or younger and 9\% children were born at home. Mean birth weight was $2891 \mathrm{~g} ; 13 \%$ of infants were classified as low birth weight ( $<2500 \mathrm{~g})$. More than half of the mothers (53\%) were illiterate or had only up to grade 5 level education. Most of the mothers $(90 \%)$ received iron supplementation during the last pregnancy and most of the iron capsules also contain folic acid. While initiation and continuation of breastfeeding is universal in this community, only half of the mothers practiced exclusive breastfeeding of their infants up to three months. Complementary feeding in the form of home-made cereal based porridge (lito) or animal or powder milk are commonly introduced at early as from one month of life due to common belief that mother milk alone is not sufficient for their children [38]. Nearly two thirds of infants below six months of age were introduced to home made cereals (lito) as complementary food whereas $10 \%$ and $7 \%$ introduced cerelac (commercially available fortified porridge) and Lactogen, respectively. Approximately $60 \%$ of infants were anaemic $(\mathrm{Hb}<110 \mathrm{~g} / \mathrm{L})$ at enrollment; after adjusting the $\mathrm{Hb}$ cut-off for altitude, the proportion increased to $70 \%$.

Table 2. Baseline characteristics among 467 healthy infants participating in micronutrient survey in Bhaktapur Nepal.

\begin{tabular}{cccc}
\hline Characteristics & \% & Mean & SD \\
\hline Age in months & & 6.8 & 2.9 \\
Age $\leqslant 6$ months & 45 & & \\
First born child & 42 & & \\
Male child & 56 & & \\
Home delivery & 9 & & 492 \\
Birth weight, gm * & & 2891 & \\
Low birth weight $(<2500$ gm) & 13 & & \\
\hline
\end{tabular}


Table 2. Cont.

\begin{tabular}{|c|c|c|c|}
\hline Characteristics & $\%$ & Mean & SD \\
\hline \multicolumn{4}{|l|}{ Demographic features: } \\
\hline Illiterate or up to grade 5 education of mother & 53 & & \\
\hline Illiterate or up to grade 5 education of father & 5 & & \\
\hline Not working mother & 65 & & \\
\hline Mother age & & 25.5 & 2.2 \\
\hline Family residing in rented house & 37 & & \\
\hline Family staying in joint family & 51 & & \\
\hline Family having own land & 54 & & \\
\hline \multicolumn{4}{|l|}{ Breastfeeding status: } \\
\hline Exclusive breastfeeding for 3 months or more $\uparrow$ & 51 & & \\
\hline Exclusive breastfeeding for 6 months or more & 17 & & \\
\hline \multicolumn{4}{|l|}{ Nutritional status: } \\
\hline Underweight (weight for age Z score $\leqslant 2$ ) & 5 & & \\
\hline Stunting (length for age $\mathrm{Z}$ score $\leqslant 2$ ) & 9 & & \\
\hline Wasting (weight for length $Z$ score $\leqslant 2$ ) & 2 & & \\
\hline Hemoglobin, $\mathrm{g} / \mathrm{L}$ & & 107 & 12 \\
\hline Anemia (hemoglobin <110 g/L) & 59 & & \\
\hline Anemia (hemoglobin $<113 \mathrm{~g} / \mathrm{L}$ ) & 70 & & \\
\hline Infection/inflammation: & & & \\
\hline C-reactive protein $>5 \mathrm{mg} / \mathrm{L} \ddagger$ & 20 & & \\
\hline
\end{tabular}

* Among 438 newborns from whom birth weights were recorded; + exclusive breastfeeding defined as child only consuming breastmilk and no other fluid or food except medicine, prevalence calculated for those who had passed the relevant age; $\ddagger$ among 463 infants.

\subsection{Plasma Concentration of Vitamins and Markers for B-Vitamin Status (MMA and tHcy)}

The mean (SD), median, and percentile distribution, as well as status and deficiencies of vitamins and metabolites, are summarized in Tables 3 and 4. The median (IQR) of plasma vitamin A, D, $\mathrm{E}, \mathrm{B}_{6}, \mathrm{~B}_{12}$ and folate were: $0.95(0.79-1.1) \mu \mathrm{mol} / \mathrm{L}, 80$ (67-93) nmol/L, $20.3(17.6-23.6) \mu \mathrm{mol} / \mathrm{L}$, $31(20.8-47.4) \mathrm{nmol} / \mathrm{L}, 232$ (165-321) pmol/L, 66.9 (45.3-96.8) nmol, respectively. Vitamin A deficiency (plasma trans retinol concentration $<0.70 \mu \mathrm{mol} / \mathrm{L}$ ) was found in $15 \%$ (95\% CI: 11-18) of infants while 65\% (95\% CI: 61-69) were classified as marginally deficient $(<1.05 \mu \mathrm{mol} / \mathrm{L})$. Corresponding figures among two to six months of age were $18 \%$ and $77 \%$, respectively.

Table 3. Mean and percentile distributions of micronutrient and total homocysteine and methylmalonic concentrations among infants in Bhaktapur, Nepal.

\begin{tabular}{|c|c|c|c|c|c|c|c|c|}
\hline Mean/Centile & $\begin{array}{c}\text { Vit A } \\
(\mu \mathrm{mol} / \mathrm{L})\end{array}$ & $\begin{array}{c}\text { Vit D } \\
(\mathrm{nmol} / \mathrm{L})\end{array}$ & $\begin{array}{c}\text { Vit E } \\
(\mu \mathrm{mol} / \mathrm{L})\end{array}$ & $\begin{array}{c}\text { Vit B } 6 \\
(\mathrm{nmol} / \mathrm{L})\end{array}$ & $\begin{array}{c}\text { Vit } B_{12} \\
(\mathrm{pmol} / \mathrm{L})\end{array}$ & $\begin{array}{c}\text { Folate } \\
(\mathrm{nmol} / \mathrm{L})\end{array}$ & $\begin{array}{c}\text { tHcy } \\
(\mu \mathrm{mol} / \mathrm{L})\end{array}$ & $\begin{array}{c}\text { MMA } \\
(\mu \mathrm{mol} / \mathrm{L})\end{array}$ \\
\hline Mean (SD) & $0.96(0.25)$ & $82(21)$ & $20.6(4.9)$ & $41.3(35.8)$ & $260(131)$ & $73(35.0)$ & $12.5(5.5)$ & $0.84(0.88)$ \\
\hline $25 \%$ & 0.79 & 67 & 17.6 & 20.8 & 165 & 45.3 & 8.6 & 0.33 \\
\hline $50 \%$ & 0.95 & 80 & 20.3 & 31 & 232 & 66.9 & 11.2 & 0.55 \\
\hline
\end{tabular}

Vit $\mathrm{A}=$ trans retinol, Vit $\mathrm{D}=25(\mathrm{OH}) \mathrm{D}$, Vit $\mathrm{E}=(\alpha$-tocopherol $)$, Vit $\mathrm{B}_{6}=$ pyridoxal $5^{\prime}$ phosphate, Vit $\mathrm{B}_{12}=$ cobalamin, $\mathrm{tHcy}=$ total homocysteine, $\mathrm{MMA}=$ methylmalonic acid. 
Table 4. Prevalence of vitamin (A, D, E, $\mathrm{B}_{6}, \mathrm{~B}_{12}$, folate) deficiencies and metabolic markers (MMA and tHcy) in healthy infants of Bhaktapur, Nepal $(n=467)$.

\begin{tabular}{|c|c|c|c|}
\hline Vitamins & $n$ & $\begin{array}{c}\% \text { below or } \\
\text { above Cut-off }\end{array}$ & $95 \% \mathrm{CI}$ \\
\hline Vitamin A (trans retinol) & 68 & 15 & 11,18 \\
\hline Marginal vitamin A & 304 & 65 & 61,69 \\
\hline Vitamin D 25(OH)D & 17 & 3.6 & $1.9,5.4$ \\
\hline Marginal vitamin D $25(\mathrm{OH}) \mathrm{D}$ & 191 & 41 & 36,45 \\
\hline Vitamin E ( $\alpha$-tocopherol) & 6 & 1.3 & $0.3,2$ \\
\hline Marginal vitamin E & 137 & 36 & 31,40 \\
\hline Vitamin $\mathrm{B}_{6}$ (pyridoxal $5^{\prime}$ phosphate) & 101 & 22 & 18,25 \\
\hline Vitamin $B_{12}$ (cobalamin) & 80 & 17 & 14,20 \\
\hline Marginal vitamin $\mathrm{B}_{12}$ (cobalamin) & 185 & 40 & 35,44 \\
\hline Folate & 0 & 0 & 0 \\
\hline Hypermethylmalonic academia & 384 & 82 & 78,85 \\
\hline Hyperhomocysteinemia & 289 & 62 & 57,66 \\
\hline
\end{tabular}

Very few infants $(<4 \%)$ were deficient in either vitamin D or vitamin E. Approximately one in five infants $(22 \%, 95 \%$ CI: 18,25$)$ were vitamin $\mathrm{B}_{6}$ deficient; and among infants without elevated CRP concentrations the prevalence was $19 \%$. Vitamin $B_{12}$ deficiency was found in $17 \%$ of the infants (95\% CI: 14, 20), whereas $40 \%$ (95\% CI: 35, 44) were considered to have marginal $\mathrm{B}_{12}$ deficiency $(<200 \mathrm{pmol} / \mathrm{L})$. While none of the infants had poor folate status $(<10 \mathrm{nmol} / \mathrm{L})$, the metabolic markers MMA and tHcy were elevated in $82 \%$ and $64 \%$ of infants, respectively. Among the infants with poor vitamin $B_{12}$ status, $93 \%$ had elevated MMA and $83 \%$ had elevated tHcy.

In addition to evaluating the prevalence of a single vitamin deficiency, we also assessed multiple vitamin deficiencies in this population. Infants who had marginal vitamin A deficiency also had $26.9 \%$, $24.7 \%$ and $31.7 \%$ marginal deficiencies of vitamins $\mathrm{D}, \mathrm{E}$, and $\mathrm{B}_{12}$, respectively. An overlap of marginal vitamin $B_{12}$ and vitamin $B_{6}$ deficiency was seen in $10.7 \%$, while $18.6 \%$ of infants were marginally deficient in both vitamin $B_{12}$ and vitamin $\mathrm{D}$. Anemic infants $(\mathrm{Hb}<110 \mathrm{~g} / \mathrm{L})$ were more likely to be deficient, or marginally deficient, in at least one vitamin. Notably, $40 \%$ of anemic infants had marginal vitamin A deficiency, $25 \%$ had marginal vitamin D deficiency, and $15 \%$ and $11 \%$ were vitamin $B_{6}$ and $\mathrm{B}_{12}$ deficient, respectively (Table 5).

Table 5. Co-existence of multiple vitamin deficiencies and anemia among 467 breastfed infants in Bhaktapur, Nepal.

\begin{tabular}{|c|c|c|c|c|c|c|c|c|c|}
\hline Vitamins & $\%$ & & & & & & & & \\
\hline Vitamin D & 0.9 & 2.3 & & & & & & & \\
\hline Marginal vit $\mathrm{D}$ & 5.3 & 25.9 & & & & & & & \\
\hline Marginal vit E & 7.7 & 24.6 & 3 & 17.5 & & & & & \\
\hline Vitamin $B_{6}$ & 4.3 & 4.3 & 2.3 & 10.2 & 0.4 & 11.3 & & & \\
\hline Marginal vit $B_{12}$ & 8.1 & 31.7 & 2 & 18.6 & 0.9 & 21.6 & 10.7 & & \\
\hline Anemia & 8.8 & 40 & 2.3 & 24.8 & 0.6 & 22.7 & 14.5 & 11.1 & 31.2 \\
\hline Deficiencies of & Vit A & Marg vit A & Vit D & Marg vit $D$ & Vit E & Marg vit E & Vit $\mathbf{B}_{6}$ & Vit $B_{12}$ & Marg vit $B_{12}$ \\
\hline
\end{tabular}

Cut off of vitamins deficiencies: vitamin $\mathrm{A} \leqslant 0.70 \mu \mathrm{mol} / \mathrm{L}$, marginal vitamin $\mathrm{A} \leqslant 1.05 \mu \mathrm{mol} / \mathrm{L}$, vitamin $\mathrm{D}$ $\leqslant 50 \mathrm{nmol} / \mathrm{L}$, marginal vitamin $\mathrm{D} \leqslant 75 \mathrm{nmol} / \mathrm{L}$, vitamin $\mathrm{E} \leqslant 9.3 \mu \mathrm{mol} / \mathrm{L}$, marginal vitamin $\mathrm{E} \leqslant 18.9 \mu \mathrm{mol} / \mathrm{L}$, vitamin $\mathrm{B}_{6} \leqslant 20 \mathrm{nmol} / \mathrm{L}$, vitamin $\mathrm{B}_{12} \leqslant 150 \mathrm{pmol} / \mathrm{L}$, marginal vitamin $\mathrm{B}_{12} \leqslant 200 \mathrm{pmol} / \mathrm{L}$. Anemia $=\mathrm{Hb}$ $<113 \mathrm{~g} / \mathrm{L}$.

\subsection{Age Related Changes of Plasma Vitamins and Metabolic Markers}

The concentrations of plasma vitamins and metabolic markers by age are shown in Figure 1. 

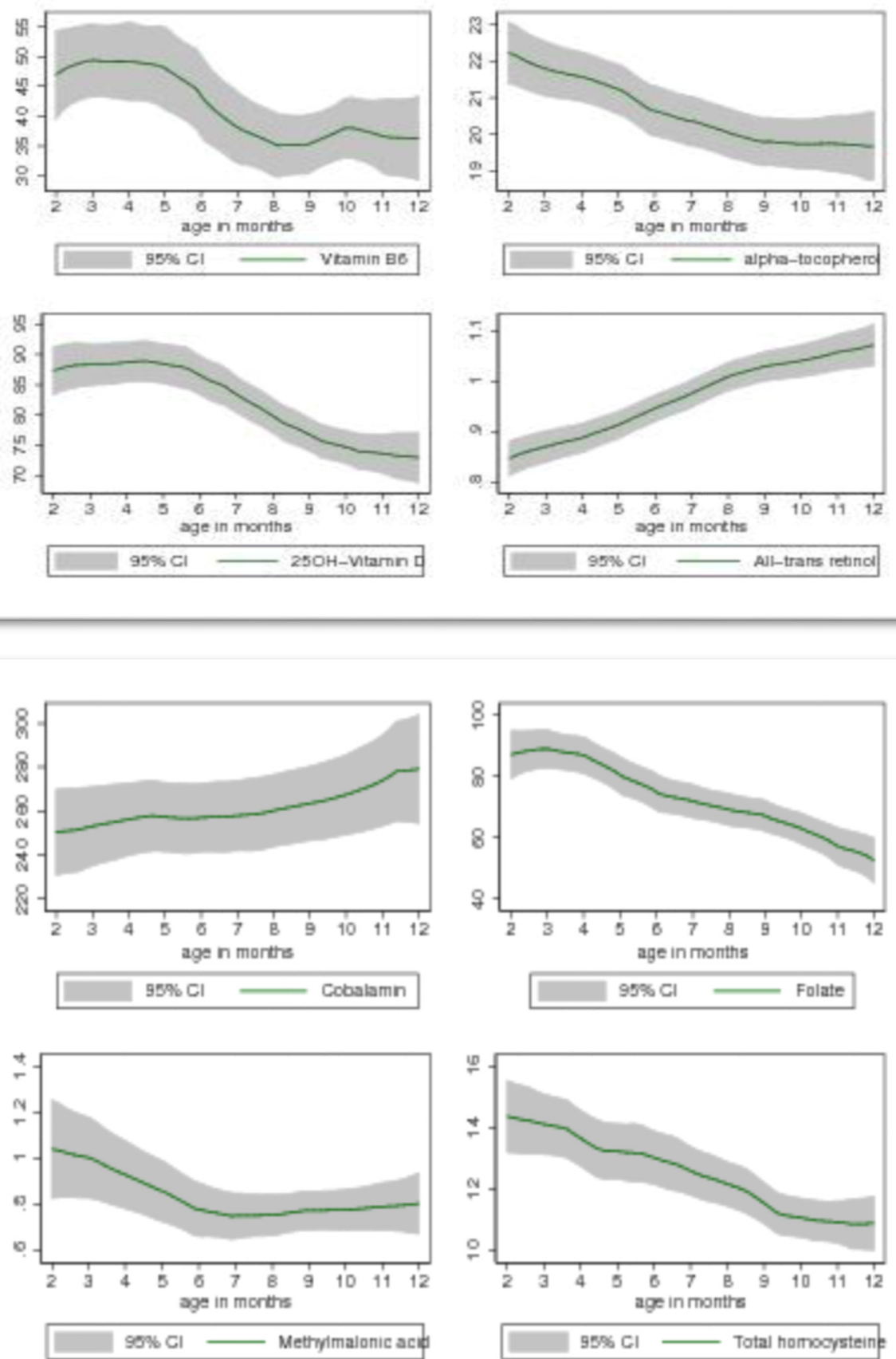

Figure 1. Association between vitamins of $\mathrm{B}_{6}$ (pyridoxal $5^{\prime}$ phosphate nmol/L), $\mathrm{E}(\alpha$-tocopherol, $\mu \mathrm{mol} / \mathrm{L}), \mathrm{D}(25(\mathrm{OH}) \mathrm{D}, \mathrm{nmol} / \mathrm{L}), \mathrm{A}($ trans retinol, $\mu \mathrm{mol} / \mathrm{L}), \mathrm{B}_{12}$ (cobalamin, pmo/L), Folate(plasma folate, $\mathrm{nmol} / \mathrm{L}), \mathrm{MMA}(\mu \mathrm{mol} / \mathrm{L})$ and $\mathrm{tHcy}(\mu \mathrm{mol} / \mathrm{L})$ with age among 467 breastfed Nepalese infants. The $\mathrm{Y}$ axis indicate the mean concentration of plasma vitamins or metabolic markers. $\mathrm{X}$ axis indicate the age of the child. The shaded area represents $95 \%$ CI of the plasma vitamins and metabolic markers.

Plasma vitamin $A$ and vitamin $B_{12}$ concentration were low at two to three months and increased throughout infancy. Plasma $25(\mathrm{OH}) \mathrm{D}, \alpha$ tocopherol, and folate were higher among two to three month olds and declined with age. The mean plasma vitamin A was $0.85 \mu \mathrm{mol} / \mathrm{L}$ among infants less than six months of age compared to a mean plasma vitamin A of $1.0 \mu \mathrm{mol} / \mathrm{L}$ among infants six months and older $(p<0.0001)$. Plasma PLP declined with increasing age, and was $10 \mathrm{nmol} / \mathrm{L}$ lower in 
infants $\geqslant$ six months of life than in younger infants $(p<0.003)$. In relation to age, tHcy and MMA were highest in younger infants (the first 6 months of life).

\subsection{Correlation Analyses}

The Spearman correlations between vitamins, metabolic markers (MMA and tHcy), and CRP are shown in Table 6. The concentrations of plasma vitamin A, $\alpha$-tocopherol, PLP, and cobalamin were positively correlated with each other. However folate was negatively associated with vitamin A and cobalamin but positively associated with vitamin D. While the concentration of tHcy was inversely associated with cobalamin and vitamin A, it was positively correlated with folate. MMA was associated negatively with cobalamin and positively with folate. CRP was inversely associated with vitamin A and PLP whereas vitamin B12 was positively associated with CRP. Vitamin A, $\alpha$ - tocopherol, PLP and Vitamin B12 were positively associated with $\mathrm{Hb}$ level. All indicators of vitamins except vitamin A and cobalamin were negatively associated with the age of the child.

Table 6. Correlations for vitamin status, MMA, tHcy, CRP, Hb and age among healthy infants of Bhaktapur Nepal $(n=467)$.

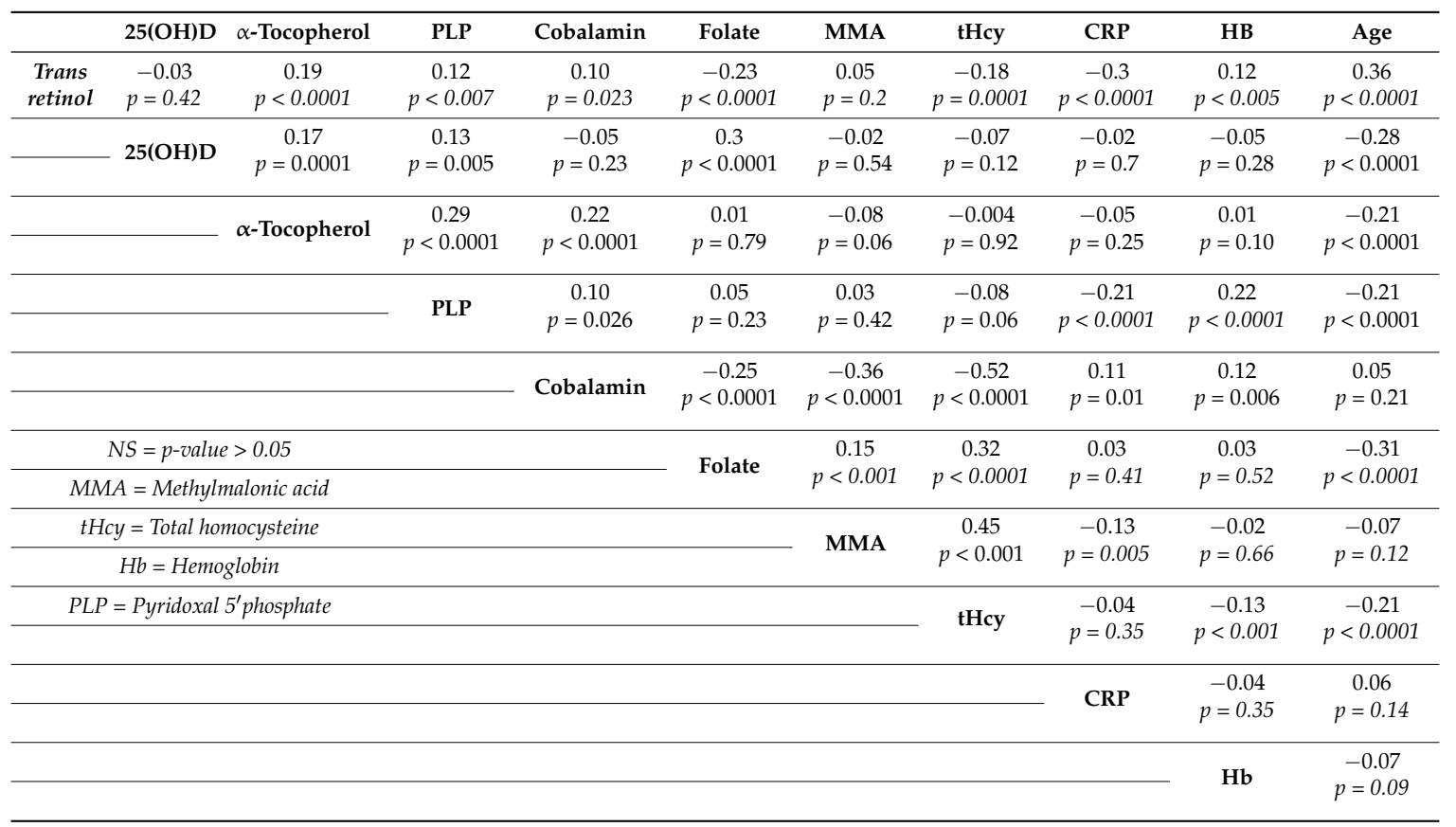

\section{Discussion}

Optimal vitamin status during infancy is important for many aspects of child health, growth, and development. We found that the prevalence of vitamin $\left(A, D, E, B_{6}\right.$, and $\left.B_{12}\right)$ and folate deficiencies in the Bhaktapur municipality of Nepal, ranged from zero to $65 \%$ using thresholds reflecting marginal deficiency for each vitamin. One of the main challenges to the interpretation of prevalence figures of biochemical parameters for young infants is the lack of age-specific cut-off values. We therefore presented the data both in terms of the proportion of infants with deficiency and marginal deficiency as well as percentiles. Despite the timing of a national bi-annual vitamin A supplementation program that targets children six months and older, the prevalence of vitamin A deficiency, and marginal vitamin A deficiency, in Bhaktapur was fairly high (15\% and 65\% respectively). These findings suggested that the prevalence of Vitamin A deficiency is almost twice as high compared to another study conducted among six to eight year-old children in the Southern Nepal [39]. The relatively low concentrations of plasma vitamin A in younger infants identified by this study may be due to low maternal intake of vitamin A rich foods during pregnancy and lactation [8] and sub-optimal breast 
milk concentrations of retinol [40]. In Nepal, cultural beliefs and food taboos restrict intake of foods (leafy vegetables and fruits) that are rich in vitamin A during pregnancy and breastfeeding [41], and low consumption of meat, fish and other animal source foods may also cause poor maternal nutritional status during pregnancy and breastfeeding. Furthermore, the relatively low coverage of vitamin A supplementation in younger children (six to 12 months) may also contribute for the low concentrations of plasma vitamin A reported in this population. While $92 \%$ of children aged 12 to 59 months received bi-annual vitamin A supplements, only $70 \%$ of children six to 12 months benefited from the national program $[8,42]$.

The prevalence of vitamin $\mathrm{D}$ and vitamin $\mathrm{E}$ deficiencies in this study population was lower than that of vitamin A, but marginal deficiencies of these vitamins were common and were seen in more than a third of infants. Unfortunately, there is limited information available on status of vitamin D and $\mathrm{E}$ from infants in the South Asia. A recent study conducted in rural Nepal found that $91.5 \%$ of pre-school children were vitamin D deficient using a threshold of $25(\mathrm{OH}) \mathrm{D}<50 \mathrm{nmol} / \mathrm{L})$ [43], indicating a substantially higher burden of vitamin D deficiency in Nepal than what we report in our study. We found only five infants who were at the threshold of $25(\mathrm{OH}) \mathrm{D}<40 \mathrm{nmol} / \mathrm{L}$, a cut off value which was used to set estimated average intake value of vitamin $\mathrm{D}$ intake and often recommended to define vitamin $\mathrm{D}$ deficiency in population. The differences between our results and those findings may be explained by differences in age, study location, methods to sample and analyse vitamin $D$, as well as sunlight exposure. While the study from rural Nepal assessed vitamin D status among pre-school children, our study population consisted of children from two to 12 months of age. Furthermore, in Bhaktapur it is common to give regular sunbaths with oil massage to newborn infants for the first three months of life. This tradition may expose infants in Bhaktapur to direct sunlight, thereby stimulating the production of vitamin D. These factors may explain the higher $25(\mathrm{OH}) \mathrm{D}$ concentrations reported in our study.

Of the water-soluble vitamins, we found a high prevalence of vitamin $B_{12}(17 \%)$ and vitamin $B_{6}$ (22\%) deficiencies, but not folate deficiency. The concentration of plasma PLP was inversely correlated with the CRP concentration. The close relationship of vitamin $\mathrm{B}_{6}$ with inflammation has been reported in other studies $[44,45]$, and there is a concern that lower plasma PLP concentration does not necessarily represent vitamin $B_{6}$ status in the presence of inflammation [46]. Together with vitamin $B_{12}$ and folate, vitamin $B_{6}$ plays a crucial role in homocysteine metabolism in the methylation cycle [47]. However, our results did not show higher plasma concentration of tHcy among infants with vitamin $\mathrm{B}_{6}$ deficiency, indicating that the majority of metabolic alteration of tHcy is related to vitamin $\mathrm{B}_{12}$ deficiency in this community.

The high folate concentration and positive correlation with tHcy may also be a result of the folate trap phenomenon [48]. In Nepal, the diet primarily consists of rice and lentils with seasonal access to green leafy vegetables. Few regularly consume meat, milk or fish, the main sources of $\mathrm{B}_{12}$ in populations lacking access to fortified foods [49]. The relatively high prevalence of marginal vitamin $B_{12}$ deficiency $(40 \%)$ among infants is consistent with the low dietary diversity observed in this population [49], and reflects the high prevalence of marginal vitamin $B_{12}$ deficiency observed among children and women from the same community, as well as in other communities across Nepal and India [50-52]. While vitamin $B_{12}$ concentration was positively correlated with age, folate concentration was inversely associated with age. This is likely explained by concentrations of folate in breast milk which is high even when mothers have a low intake of this nutrient. According to national health recommendations, pregnant mothers regularly receive folic acid and iron supplements throughout the pregnancy and lactation period [53].

Most of the infants had more than one marginal vitamin deficiency. This is consistent with other studies from Nepal that report a high burden of multiple micronutrient deficiencies among pregnant and lactating mothers and children $[20,36,39]$. The concentrations of vitamin $A, E, B_{6}$ and $B_{12}$ in our study were positively correlated. We also found a correlation between anemia and deficiencies in vitamins $\mathrm{A}, \mathrm{B}_{6}, \mathrm{~B}_{12}$ and folate, highlighting the potential contributions of other nutrients to the etiology 
of anemia among these young infants. Iron deficiency anemia is consistently reported as one of the main public health problems in Nepal [54] [20,36,39]. Depleted iron stores were found among 20\% of infants only whereas $70 \%$ were anemic $(\mathrm{Hb}<113 \mathrm{~g} / \mathrm{L})$, a detailed description of other iron parameters have been published elsewhere [55]. Poor intake of iron rich complementary foods and physiological anemia at three to seven months of age are probably underlying causes of anemia in this population. Young infants are entirely dependent on breast milk which is low in iron concentration [56], and local complementary foods are usually not fortified with iron [38].

Although they are only needed in tiny amount, micronutrient malnutrition is a public health problem in developing countries. Most infant diets in the community contained insufficient amounts of vitamins and minerals because of poor food diversity. To prevent deficiencies of micronutrients, food fortification should be expanded from current pilot projects in some parts of Nepal, and further efforts to diversify the food supply are needed $[57,58]$.

\section{Conclusions}

In this peri-urban population in the Kathmandu Valley, we observed a high prevalence of marginal deficiency of vitamins among breastfed infants. The levels of vitamin A deficiency documented among infants in this study highlight the importance of continued vitamin A supplementation campaigns, particularly for infants six to 12 months of age who have lower coverage rates than children aged 12 to 59 months through the national vitamin A program. Our findings also illustrate the importance of expanding food fortification and dietary diversification programs targeting children and women.

Acknowledgments: We are grateful for the contribution of field supervisor Chandrawati Chitrakar, and data managers Samir K.C., Uma Regmi for their contribution on data collection and entry. We also thank founder Shyam Dhaubhadel of Siddhi Memorial Hospital for his cooperation to conduct the study. Funding: The present study was funded grants from the Research Council of Norway (project No. 172226), from the GCRieber Funds, and the South-Eastern Norway Regional Health Authority (grant No. 2012090), and by the USAID Feed the Future Innovation Laboratory for Nutrition.

Author Contributions: The contributions of the authors were as follows: T.A.S. (principal investigator), R.K.C., S.H., and P.S.S. designed the research; R.K.C., T.A.S., M.U. and S.H. conducted the research; Ø.M. and P.M.U. were responsible for the biochemical analyses; M.U., T.A.S., R.K.C. and A.L.T.L. analyzed the data; M.U. wrote the paper; L.G., T.A.S., A.L.T.L. and W.W.F. contributed to writing the paper. M.U. and T.A.S. had primary responsibility for the final content. All authors read and approved the final manuscript.

Conflicts of Interest: The authors declare no conflict of interest.

\section{References}

1. Black, R.E.; Victora, C.G.; Walker, S.P.; Bhutta, Z.A.; Christian, P.; de Onis, M.; Ezzati, M.; Grantham-McGregor, S.; Katz, J.; Martorell, R.; et al. Maternal and child undernutrition and overweight in low-income and middle-income countries. Lancet 2013, 382, 427-451. [CrossRef]

2. Singh, M. Role of micronutrients for physical growth and mental development. Indian J. Pediatr. 2004, 71, 59-62. [CrossRef] [PubMed]

3. WHO. The World Health Report 2001: Reducing Risks, Promoting Healthy Life; World Health Organization: Geneva, Switzerland, 2001.

4. Bhandari, S.; Banjara, M.R. Micronutrients deficiency, a hidden hunger in Nepal: Prevalence, causes, consequences, and solutions. Int. Sch. Res. Not. 2015, 2015, 9. [CrossRef]

5. WHO. Guiding Principles for Feeding Non-Breastfed Children 6-24 Months of Age; World Health Organization: Geneva, Switzerland, 2005.

6. Stephensen, C.B. Vitamin A, infection, and immune function. Annu. Rev. Nutr. 2001, 21, 167-192. [CrossRef] [PubMed]

7. Thurnham, D.I. Micronutrients and immune function: Some recent developments. J. Clin. Pathol. 1997, 50, 887-891. [CrossRef] [PubMed]

8. MOHP (Ministry of Health and Population (Nepal)). Nepal Demographic and Health Survey 2011; New Era, Calverton, Maryland and Icf International Inc.: Kathmandu, Nepal, 2011. 
9. Walker, V.P.; Modlin, R.L. The vitamin D connection to pediatric infections and immune function. Pediatr. Res. 2009, 65, 106R-113R. [CrossRef] [PubMed]

10. Pletz, M.W.; Terkamp, C.; Schumacher, U.; Rohde, G.; Schutte, H.; Welte, T.; Bals, R.; Group, C.A.-S. Vitamin $\mathrm{D}$ deficiency in community-acquired pneumonia: Low levels of $1,25(\mathrm{OH}) 2 \mathrm{D}$ are associated with disease severity. Respir. Res. 2014, 15, 53. [CrossRef] [PubMed]

11. Jorde, R.; Mathiesen, E.B.; Rogne, S.; Wilsgaard, T.; Kjaergaard, M.; Grimnes, G.; Schirmer, H. Vitamin D and cognitive function: The tromso study. J. Neurol. Sci. 2015, 355, 155-161. [CrossRef] [PubMed]

12. Jovanovich, A.J.; Ginde, A.A.; Holmen, J.; Jablonski, K.; Allyn, R.L.; Kendrick, J.; Chonchol, M. Vitamin D level and risk of community-acquired pneumonia and sepsis. Nutrients 2014, 6, 2196-2205. [CrossRef] [PubMed]

13. Mithal, A.; Wahl, D.A.; Bonjour, J.P.; Burckhardt, P.; Dawson-Hughes, B.; Eisman, J.A.; El-Hajj Fuleihan, G.; Josse, R.G.; Lips, P.; Morales-Torres, J.; et al. Global vitamin D status and determinants of hypovitaminosis D. Osteoporos. Int. 2009, 20, 1807-1820. [CrossRef] [PubMed]

14. Dror, D.K.; Allen, L.H. Vitamin E deficiency in developing countries. Food Nutr. Bull. 2011, 32, $124-143$. [CrossRef] [PubMed]

15. Strand, T.A.; Taneja, S.; Ueland, P.M.; Refsum, H.; Bahl, R.; Schneede, J.; Sommerfelt, H.; Bhandari, N. Cobalamin and folate status predicts mental development scores in north Indian children 12-18 months of age. Am. J. Clin. Nutr. 2013, 97, 310-317. [CrossRef] [PubMed]

16. Kvestad, I.; Taneja, S.; Kumar, T.; Hysing, M.; Refsum, H.; Yajnik, C.S.; Bhandari, N.; Strand, T.A.; Folate and Vitamin B12 Study Group. Vitamin B12 and folic acid improve gross motor and problem-solving skills in young north Indian children: A randomized placebo-controlled trial. PLoS ONE 2015, 10, e0129915. [CrossRef] [PubMed]

17. Strand, T.A.; Taneja, S.; Kumar, T.; Manger, M.S.; Refsum, H.; Yajnik, C.S.; Bhandari, N. Vitamin B-12, folic acid, and growth in 6- to 30-month-old children: A randomized controlled trial. Pediatrics 2015, 135, e918-e926. [CrossRef] [PubMed]

18. Maggini, S.; Wintergerst, E.S.; Beveridge, S.; Hornig, D.H. Selected vitamins and trace elements support immune function by strengthening epithelial barriers and cellular and humoral immune responses. Br. J. Nutr. 2007, 98, S29-S35. [CrossRef] [PubMed]

19. Horton, S.; Begin, F.; Greig, A.; Lakshman, A. Micronutrient supplements for child survival (vitamin A and zinc). Cph. Consens. Cent. 2009, 1, 21-27.

20. Henjum, S.; Manger, M.; Skeie, E.; Ulak, M.; Thorne-Lyman, A.L.; Chandyo, R.; Shrestha, P.S.; Locks, L.; Ulvik, R.J.; Fawzi, W.W.; et al. Iron deficiency is uncommon among lactating women in urban Nepal, despite a high risk of inadequate dietary iron intake. Br. J. Nutr. 2014, 112, 132-141. [CrossRef] [PubMed]

21. WHO. World Health Organization. Anthro 2005, Beta Version, feb17th, 2006: Software for Assessing Growth and Development of the World's Children. Geneva. 2006. Available online: http://www.Who.Int/ childgrowth/software/en/ (accessed on 6 July 2014).

22. WHO. Indicators for Assessing Infant and Young Child Feeding Practices: Conclusions of a Consensus Meeting Held 6-8 November 2007 in Washington D.C., USA; WHO: Geneva, Switzerland, 2007.

23. Kelleher, B.P.; Walshe, K.G.; Scott, J.M.; O’Broln, S.D. Microbiological assay for vitamin B12 with use of a colistin-sulfate-resistant organism. Clin. Chem. 1987, 33, 52-54. [PubMed]

24. O'Broin, S.; Kelleher, B. Microbiological assay on microtitre plates of folate in serum and red cells. J. Clin. Pathol. 1992, 45, 344-347. [CrossRef] [PubMed]

25. BEVITAL. Assesments of Nutrinal Status by Vitamins Marker. Laboratoriebygget, 9 ETG Jonas Lies veg 875021 Bergen, Norway. Available online: http:/ /www.bevital.no/ (accessed on 17 February 2015).

26. Windelberg, A.; Arseth, O.; Kvalheim, G.; Ueland, P.M. Automated assay for the determination of methylmalonic acid, total homocysteine, and related amino acids in human serum or plasma by means of methylchloroformate derivatization and gas chromatography-mass spectrometry. Clin. Chem. 2005, 51, 2103-2109. [CrossRef] [PubMed]

27. Midttun, O.; Hustad, S.; Ueland, P.M. Quantitative profiling of biomarkers related to B-vitamin status, tryptophan metabolism and inflammation in human plasma by liquid chromatography/tandem mass spectrometry. Rapid Commun. Mass Spectrom. 2009, 23, 1371-1379. [CrossRef] [PubMed] 
28. Midttun, O.; Ueland, P.M. Determination of vitamins A, D and E in a small volume of human plasma by a high-throughput method based on liquid chromatography/tandem mass spectrometry. Rapid Commun. Mass Spectrom. 2011, 25, 1942-1948. [CrossRef] [PubMed]

29. WHO. Iron Deficiency Anemia. Assesment, Prevention and Control. A Guide for Programme Manager; WHO: Geneva, Switzerland, 2001.

30. INACG (International Nutritional Anemia Consultative Group). Adjusting hemoglobin values in program surveys. In Inacg Secretariat ilsi Human Nutrition Institute One Thomas Circle, Ninth Floor Internet; INACG: Washington, DC, USA, 2002.

31. De Benoist, B. Conclusions of a who technical consultation on folate and vitamin B12 deficiencies. Food Nutr. Bull. 2008, 29, S238-S244. [CrossRef]

32. Morris, M.S.; Picciano, M.F.; Jacques, P.F.; Selhub, J. Plasma pyridoxal 5'-phosphate in the us population: The national health and nutrition examination survey, 2003-2004. Am. J. Clin. Nutr. 2008, 87, 1446-1454. [PubMed]

33. Allen, L.; de Benoist, B.; Dary, O.; Hurrell, R. Guidelines on Food Fortification with Micronutrients-Who/Fao; World Health Organization: Geneva, Switzerland, 2006.

34. WHO. Global prevalence of vitamin a deficiency in populations at risk, 1995-2005. In Who Global Database on Vitamin a Deficiency; WHO: Geneva, Switzerland, 2009.

35. IOM (Institute of Medicine). Dietary Reference Intakes for Calcium and Vitamin D; The National Academy Press: Washington, DC, USA, 2011.

36. Jiang, T.; Christian, P.; Khatry, S.K.; Wu, L.; West, K.P., Jr. Micronutrient deficiencies in early pregnancy are common, concurrent, and vary by season among rural Nepali pregnant women. J. Nutr. 2005, 135, 1106-1112. [PubMed]

37. Thurnham, D.I.; Mburu, A.S.; Mwaniki, D.L.; De Wagt, A. Micronutrients in childhood and the influence of subclinical inflammation. Proc. Nutr. Soc. 2005, 64, 502-509. [CrossRef] [PubMed]

38. Ulak, M.; Chandyo, R.K.; Mellander, L.; Shrestha, P.S.; Strand, T.A. Infant feeding practices in bhaktapur, Nepal: A cross-sectional, health facility based survey. Int. Breastfeed. J. 2012, 7, 1. [CrossRef] [PubMed]

39. Schulze, K.J.; Christian, P.; Wu, L.S.; Arguello, M.; Cui, H.; Nanayakkara-Bind, A.; Stewart, C.P.; Khatry, S.K.; LeClerq, S.; West, K.P., Jr. Micronutrient deficiencies are common in 6- to 8-year-old children of rural Nepal, with prevalence estimates modestly affected by inflammation. J. Nutr. 2014, 144, 979-987. [CrossRef] [PubMed]

40. Allen, L.H. Maternal micronutrient malnutrition: Effects on breast milk and infant nutrition, and priorities for intervention. SCN News 1994, 21-24.

41. Gittelsohn, J.; Thapa, M.; Landman, L.T. Cultural factors, caloric intake and micronutrient sufficiency in rural Nepali households. Soc. Sci. Med. 1997, 44, 1739-1749. [CrossRef]

42. Nguyen, A.M.; Grover, D.S.; Sun, K.; Raju, V.K.; Semba, R.D.; Schaumerg, D.A. Coverage of the vitamin A supplementation programme for child survival in Nepal: Success and challenges. Paediatr. Int. Child Health 2012, 32, 233-238. [CrossRef] [PubMed]

43. Avagyan, D.; Neupane, S.P.; Gundersen, T.E.; Madar, A.A. Vitamin D status in pre-school children in rural Nepal. Public Health Nutr. 2016, 19, 470-476. [CrossRef] [PubMed]

44. Friso, S.; Jacques, P.F.; Wilson, P.W.; Rosenberg, I.H.; Selhub, J. Low circulating vitamin B(6) is associated with elevation of the inflammation marker C-reactive protein independently of plasma homocysteine levels. Circulation 2001, 103, 2788-2791. [CrossRef] [PubMed]

45. Morris, M.S.; Sakakeeny, L.; Jacques, P.F.; Picciano, M.F.; Selhub, J. Vitamin B-6 intake is inversely related to, and the requirement is affected by, inflammation status. J. Nutr. 2010, 140, 103-110. [CrossRef] [PubMed]

46. Vasilaki, A.T.; McMillan, D.C.; Kinsella, J.; Duncan, A.; O’Reilly, D.S.; Talwar, D. Relation between pyridoxal and pyridoxal phosphate concentrations in plasma, red cells, and white cells in patients with critical illness. Am. J. Clin. Nutr. 2008, 88, 140-146. [PubMed]

47. Joosien, E.; van den Berg, A.; Riezler, R.; Naurath, H.J.; Lindenbaum, J.; Stabler, S.P.; Allen, R.H. Metabolic evidence that deficiencies of vitamin B-12 (cobalamin), folate, and vitamin B-6 occur commonly in elderly people. Am. J. Clin. Nutr. 1993, 58, 468-476.

48. Scott, J.M.; Weir, D.G. The methyl folate trap. A physiological response in man to prevent methyl group deficiency in kwashiorkor (methionine deficiency) and an explanation for folic-acid induced exacerbation of subacute combined degeneration in pernicious anaemia. Lancet 1981, 2, 337-340. [CrossRef] 
49. Henjum, S.; Torheim, L.E.; Thorne-Lyman, A.L.; Chandyo, R.; Fawzi, W.W.; Shrestha, P.S.; Strand, T.A. Low dietary diversity and micronutrient adequacy among lactating women in a peri-urban area of Nepal. Public Health Nutr. 2015, 18, 3201-3210. [CrossRef] [PubMed]

50. Ulak, M.; Chandyo, R.K.; Adhikari, R.K.; Sharma, P.R.; Sommerfelt, H.; Refsum, H.; Strand, T.A. Cobalamin and folate status in 6 to 35 months old children presenting with acute diarrhea in bhaktapur, Nepal. PLoS ONE 2014, 9, e90079. [CrossRef] [PubMed]

51. Taneja, S.; Strand, T.A.; Kumar, T.; Mahesh, M.; Mohan, S.; Manger, M.S.; Refsum, H.; Yajnik, C.S.; Bhandari, N. Folic acid and vitamin B-12 supplementation and common infections in 6-30-month-old children in india: A randomized placebo-controlled trial. Am. J. Clin. Nutr. 2013, 98, 731-737. [CrossRef] [PubMed]

52. Hay, G.; Johnston, C.; Whitelaw, A.; Trygg, K.; Refsum, H. Folate and cobalamin status in relation to breastfeeding and weaning in healthy infants. Am. J. Clin. Nutr. 2008, 88, 105-114. [PubMed]

53. Bjorke-Monsen, A.L.; Ueland, P.M. Cobalamin status in children. J. Inherit. Metab. Dis. 2011, 34, 111-119. [CrossRef] [PubMed]

54. Siegel, E.H.; Stoltzfus, R.J.; Khatry, S.K.; Leclerq, S.C.; Katz, J.; Tielsch, J.M. Epidemiology of anemia among 4- to 17-month-old children living in south central Nepal. Eur. J. Clin. Nutr. 2006, 60, 228-235. [CrossRef] [PubMed]

55. Chandyo, R.K.; Henjum, S.; Ulak, M.; Thorne-Lyman, A.L.; Ulvik, R.J.; Shrestha, P.S.; Locks, L.; Fawzi, W.; Strand, T.A. The prevalence of anemia and iron deficiency is more common in breastfed infants than their mothers in bhaktapur, Nepal. Eur. J. Clin. Nutr. 2015. [CrossRef] [PubMed]

56. Martti, A.; Siimes, E.V.; Kuitunen, P. Breast milk iron-A declining concentration during the course of lactation. Acta Paediatr. 1979, 68, 29-31.

57. Hoddinott, J.; Rosegrant, M.; Torero, M. Hunger and Malnutrition, Copenhagen Consesus; Copenhagen Consensus Center: Copenhagen, Denmark, 2012.

58. Jefferds, M.E.; Mirkovic, K.R.; Subedi, G.R.; Mebrahtu, S.; Dahal, P.; Perrine, C.G. Predictors of micronutrient powder sachet coverage in Nepal. Mater. Child Nutr. 2015, 11, 77-89. [CrossRef] [PubMed]

(C) 2016 by the authors; licensee MDPI, Basel, Switzerland. This article is an open access article distributed under the terms and conditions of the Creative Commons by Attribution (CC-BY) license (http://creativecommons.org/licenses/by/4.0/). 